\title{
Práticas de inserção de professoras na escola pública galega: formação ou seleção?
}

\author{
Marisa Narcizo Sampaio \\ Universidade Federal do Rio Grande do Norte - Brasil
}

\begin{abstract}
Resumo
O artigo relata pesquisa realizada com o objetivo de conhecer a prática cotidiana da incorporação de novos professores na escola pública da Galícia. A aproximação à realidade aconteceu por meio de pesquisa documental, realização de visitas a escolas púbicas em duas cidades e entrevistas com quatro professoras novatas e com três de suas tutoras. Na discussão dos dados, realizada com base em estudos de Certeau, Morin e Foucault, destaca-se entre as tensões percebidas a importância dedicada na lei à formação e apoio aos profissionais iniciantes, associada à avaliação e controle do seu trabalho, ainda como candidatos a uma vaga efetiva.

Palavras-chave: Professoras Inciantes, Formação continuada de Professores, Avaliação.
\end{abstract}

\section{Abstract}

The article reports a research carried out in order to meet the daily practice of new teachers' incorporation in public schools in Galicia. The approach to reality ws made with documental research, visits to pubic schools in two cities and interviews with four novice teachers and three of his tutors. In the discussion of the data based on Certeau, Morin and Foucault studies, revealed the tensions between the importance dedicated by law to training and support the novice professionals associated with the evaluation and control of their work, even as candidate an effective job.

Keywords: Novice Teachers, Teachers education, Evaluation

Muito se discute sobre a dificuldade da escola em lidar com desafios há muito postos: garantir formação integral e de qualidade que signifique possibilidade de emancipação e expressão para todas as crianças, jovens e adultos. Longe de querer imputar responsabilidade única aos professores por esta dificuldade que é conjuntural e institucional, penso, em conformidade com Torres Santomé (2006), que não é possível construir um projeto de educação mais humano, justo e democrático, sem um grupo de professores/professoras bem formado e motivado.

Dessa forma, defendo uma formação permanente de professores e professoras realizada e fundamentada no cotidiano da escola, em suas práticas pedagógicas e relações coletivas, e destaco o início da docência como uma etapa especial deste processo formativo contínuo. Entendo esta etapa como diferenciada de outras porque, nela, o professorado iniciante na carreira docente deve desenvolver uma gama ampla e complexa de aprendizagens para enfrentar e superar os desafios, dilemas e peculiaridades desta fase. Diferentes autores,
Eirín; García; Montero (2009); Guarnieri (2005); Huberman (2000); Imbernón (1994); Marcelo Garcia (1999); Nono (2011), concordam na preocupação com esta etapa da carreira e a necessidade de atenção, de acompanhamento e de programas que auxiliem os novos docentes a integrarem-se à rotina e à cultura da profissão.

$\mathrm{O}$ investimento neste espaço/tempo da carreira em que os novos professores/professoras consolidam conhecimentos, práticas, atitudes, valores é imprescindível para evitar que aprendam a repetir o mesmo (GUARNIERI, 2005; IMBERNÓN, 1994), já que quando estudante o/a novo/a professor/professora "transita pelo sistema educativo e assume uma determinada visão da educação, marcada, por vezes, por estereótipos e imagens da docência difíceis de serem superados” (NONO \& MIZUKAMI, 2006, p.383).

Os pesquisadores mencionados coincidem na maior parte das dificuldades que levantam sobre o trabalho neste período, a saber: insuficiência de material didático; problemas com horário; tratamento das diferenças individuais na sala de aula; disciplina na sala de aula; como motivar os alunos; relação com as famílias; elaboração do planejamento; avaliação; mediação pedagógica; avaliação e relação professor-aluno; isolamento e as poucas oportunidades de discutir coletivamente sobre os desafios enfrentados; falta de apoio; condições precárias no local; o contexto escolar e as relações que se estabelecem (dificuldades e cobranças dos pares), a falta de espaço para expor dúvidas; o próprio trabalho de sala de aula: o que e como ensinar, como avaliar, como lidar com os alunos com mais dificuldades, como se relacionar com os alunos. Resumindo, em conformidade com Nóvoa (2009), este assunto é o mais importante em termos de estudo para contribuir com a formação de professores. Para ele os primeiros anos de atuação profissional deviam ser anos superprotegidos, integrados aos colegas e acompanhados, e é tudo o contrário.

Estas preocupações levaram-me a buscar conhecer alternativas de formação continuada para os profissionais que iniciam carreira, tendo como foco a escola pública aqui concebida como espaço democrático a que todos devem ter acesso e permanência com sucesso. Como no Brasil não existe um procedimento oficial para a realização deste acompanhamento especial no início da atuação docente, seja com programas formativos específicos ou não, interessei-me em conhecer um sistema educativo em que esta iniciativa já fosse uma 
realidade. A Espanha apresentou-se como possibilidade já que está entre os países que oferecem apoio diferenciado em relação aos professores iniciantes, de acordo com a Lei Orgânica de Educação (2006). Esta lei trata, no seu Artigo 101, da incorporação à docência nas escolas públicas em forma de acompanhamento dos professores e professoras no primeiro ano de exercício profissional por colegas com mais experiência que cumprem a função de tutores. Assim, considera que a formação inicial dos novos docentes será complementada e continuada com a tutoria e o acompanhamento destes colegas mais experientes.

A partir desta Lei Orgânica de 2006, foi publicado o Real Decreto de 276/2007 que regulamenta o ingresso, acesso e aquisição de novas especialidades nos corpos docentes de todas as comunidades autônomas e no capítulo V do título III especifica o acompanhamento de todos os professores e professoras aprovados em concursos para a rede pública como profissionais em práticas, durante um período de três meses a um ano letivo, a ser adaptado e detalhado na organização dos concursos públicos por cada comunidade autônoma, de acordo com seu contexto.

Com objetivo conhecer na prática as atividades, a rotina e os dispositivos de acolhimento efetivados nas escolas públicas espanholas para inserção e formação dos professores e professoras iniciantes, realizei uma pesquisa no ano de 2014, visitando escolas na Galícia e fazendo entrevistas com professoras durante seu primeiro ano de atuação na rede pública de ensino (SAMPAIO, 2015).

Neste trabalho tenho a intenção de relatar o caminho percorrido para chegar às professoras e ainda explorar uma das tensões percebidas no contato com a realidade: a contradição e a complexidade que marcam as relações entre o discurso da lei sobre a importância da formação do professorado iniciante, convivendo com a avaliação do seu trabalho, ainda como candidatos e candidatas a uma vaga efetiva na rede pública.

\section{Aproximação com a realidade e suas práticas cotidianas}

A aproximação com a prática do acompanhamento da incorporação à escola pública de novos profissionais na Espanha e seus mecanismos de inserção e formação, começou com a identificação das escolas que haviam recebido professoras iniciantes no ano letivo de 2013-2014. Na página eletrônica da Xunta de Galícia encontrei o edital do concurso ocorrido no ano de 2013 para professorado de Primária e Educação Infantil nas seguintes especialidades: Pedagogia Terapêutica; Audição e Linguagem; Língua Inglesa para Educação Infantil e Primária; e Educação Infantil. As provas foram realizadas em julho e o resultado final divulgado no mesmo mês, já com a designação dos aprovados para as escolas. Os professores e professoras aprovados começaram a trabalhar no mês de setembro do mesmo ano.

O concurso foi constituído de uma prova escrita sobre conhecimentos pedagógicos e duas provas práticas com apresentação de planejamentos de aula e de unidade didática para uma banca de cinco docentes avaliadores. Os aprovados nesta fase foram avaliados e pontuados também em relação à experiência, publicações e cursos realizados.

Dentre as especialidades contempladas pelo concurso (já mencionadas), escolhi fazer contato com as professoras de Educação Infantil, porque atuo como docente no curso de Pedagogia da Universidade Federal do Rio Grande do Norte, que também habilita profissionais para esta especialidade. Nesta busca, foram identificadas 45 escolas em toda a Galícia que haviam recebido professoras aprovadas no concurso de 2013, e selecionei para a pesquisa as estavam mais próximas considerando minha localização, num total de cinco escolas nas cidades de A Coruña e Santiago de Compostela. Dessas, uma havia recebido uma professora nova na rede, mas com muitos anos de experiência no magistério, e, nas demais, todas as recém-chegadas eram professoras iniciantes na profissão.

Mediante contato telefônico com a direção de cada escola, fui autorizada a visitar a instituição e conversar com as novas professoras e suas tutoras. Assim, estive em quatro Centros de Educação Infantil e Primária CEIP - nos meses de abril e maio de 2014 e conversei com sete professoras de Educação Infantil, sendo quatro professoras iniciantes e suas respectivas tutoras do período de práticas, com exceção de uma tutora com quem não pude conversar por questões relacionadas ao seu horário.

Todas estas escolas, duas em Santiago de Compostela e duas em A Coruña, possuem espaços para secretaria, direção, sala de professores, biblioteca, sala do coordenador geral, sala do zelador, um hall de entrada amplo e parque infantil. Nos seus corredores estavam expostos trabalhos dos alunos, com temas alusivos a datas comemorativas e a projetos trabalhados na época, informações às famílias e prestação de contas. Em uma delas havia também exposição de livros no hall de entrada.

As entrevistas foram seguidas por roteiros diferentes, que perguntavam para as novas professoras: como estava sendo o acompanhamento; como eram as atividades de formação; que considerações podia fazer sobre a validade deste período; que dificuldades tinha e o que mais ajudou a superá-las. Para as professoras tutoras foi perguntado: como era o acompanhamento à professora iniciante; como eram as atividades de formação e quem as organizava e oferecia; que semelhanças e diferenças percebiam entre o seu início de carreira e o das professoras de agora.

As professoras entrevistadas assinaram autorização para uso de seus depoimentos, que foram gravados, com exceção de outra das tutoras que pediu para não ser gravada, pois ficaria inibida. Apesar de um único contato, as conversas foram produtivas e se desenvolveram como conversas informais que muitas vezes extrapolaram estes roteiros.

As professoras iniciantes entrevistadas tinham idade entre 25 e 29 anos, estudaram nas universidades de Santiago de Compostela, A Coruña e Ourense. Duas delas não possuíam nenhuma experiência anterior na 
docência; uma possuía experiência de um ano em uma creche privada e outra possuía experiências de dois anos como substituta em Educação Infantil na rede pública. Duas delas professoras iniciaram já com uma turma própria e tiveram como tutoras companheiras que lecionavam na mesma etapa da Educação Infantil, em turmas de quatro e de cinco anos. As outras duas professoras novatas passaram o período de práticas como professoras de apoio, cumprindo funções diversificadas.

Como em outras dimensões da vida humana a inserção das professoras na escola pública galega caracteriza-se pela complexidade e, a aproximação com o que se passa na prática por meio da narrativa das professoras faz com que a lei comece a ganhar vida e revelar suas tensões e contradições. Assim, foi possível perceber os matizes dados à lei no cotidiano das escolas e refletir sobre as tensões que atravessam as relações, especialmente no que se refere às ambíguas determinações legais que definem este momento como necessário à formação docente para a melhoria da qualidade da educação e, ao mesmo tempo, o revestem de um caráter avaliativo e seletivo.

Na próxima parte pretendo discutir sobre esta questão: o período práticas não é encarado oficialmente apenas como um período de aprendizagem, adaptação e socialização do novo profissional, mas fundamentalmente o contrário: é um período em que o novo professor ou professora será avaliado/a por seus conhecimentos e capacidades didáticas, podendo ser reprovado/a para a continuidade da sua carreira na rede pública. O próprio nome do título III da lei "Do sistema de ingresso", onde se inserem os procedimentos relacionados aos professores e professoras que ingressam no magistério público, já deixa claro que não se trata de um programa de apoio aos docentes iniciantes, mas sim de um procedimento para completar a avaliação e a entrada dos profissionais na rede. Corroborando com esta constatação, Eirín; García; Montero (2009) consideram que estas disposições legais constituem um processo burocrático que pouco contribui para o desenvolvimento profissional, já que limitam a iniciação docente a um período determinado de antemão para todos, que definem a designação do tutor por uma comissão integrada pelo chefe da supervisão regional, supervisores educacionais e diretores de escolas, e atrelam este período ao processo de seleção dos novos decentes.

\section{Período de práticas: formação ou seleção?}

No edital publicado pela Xunta de Galícia em 2013 convocando o concurso de provas e títulos para professores, o período de práticas estava previsto como uma fase de duração de quatro meses, definido, em conformidade com o real decreto de 2007, como "parte do procedimento seletivo e tem por objeto a comprovação de que o aspirante possui as capacidades didáticas necessárias para o exercício da docência" (GALÍCIA, 2013, p. 9900, tradução minha). Para isso, o edital já previa dar ao tutor ou tutora o poder de controlar o desempenho do(a) novo(a) professor ou professora preenchendo um formulário sobre suas atividades, e ainda de produzir um relatório com parecer final sobre sua aprovação ou não como funcionário(a) efetivo(a). Ainda segundo o edital, caberia também à direção da escola avaliar a contribuição e inserção do(a) novo(a) professor(a) às atividades da instituição. Todos estes documentos deveriam ser entregues à comissão qualificadora para avaliação e parecer final. As docentes em práticas, deveriam elaborar um relatório-memorial ao final do período, no qual fariam uma avaliação global da sua atividade, assim como das dificuldades encontradas e dos apoios recebidos. Neste memorial deveriam relatar como passaram por este período, que atividades desenvolveram, quais as principais dificuldades e desafios enfrentados e o que aprenderam sobre a escola, fazendo uma avaliação geral do trabalho realizado. Se o(a) funcionário(a) em práticas não fosse aprovado(a) neste período, teria outra chance no ano letivo seguinte para realizar as práticas.

Vejamos como isso acontecia na prática.

Uma das professoras iniciantes que assumiu o papel de professora de apoio durante o período de práticas, teve dificuldades com esta função. Sua tarefa principal era substituir em classe duas professoras da equipe gestora nas horas em que estas tinham que exercer suas funções administrativas. Dessa forma, quando estava com as turmas, não tinha o acompanhamento das professoras titulares e sua maior dificuldade era ser responsável pelos grupos em alguns momentos, tendo que dar continuidade ao trabalho que as professoras titulares estavam desenvolvendo, mas não tendo discutido o planejamento nem as atividades com elas. Nestes momentos dedicava-se a fazer jogos e atividades de artes plásticas com os alunos e se sentia frustrada por não fazer o trabalho pedagógico completo. Sentiu-se perdida até o momento em que as titulares perceberam sua angústia e sua dificuldade e retomaram a orientação ao seu trabalho, dando-lhe tarefas específicas que complementavam o trabalho que elas vinham fazendo com a turma. A professora novata descreveu este momento como muito problemático, mas que foi superado com o diálogo com as companheiras, com a proposta de mudança no tipo de trabalho e com a decisão dela de aceitar a situação de não ser a professora titular. Ela diz ter sobrevivido, usando o mesmo termo com que Huberman (2000) descreve esta primeira fase da carreira docente.

Esta professora relatou também que tentou se adaptar e que abriu mão do enfrentamento, de um lado pela tentativa de diálogo que foi estabelecida pelas colegas, mas também, de outro lado por entender que sua situação na escola era passageira, que logo estaria com sua matrícula definitiva em outra escola e principalmente porque ela queria ser aprovada e para isso dependia da tutora. Na minha compreensão, agindo assim a professora se utilizou do que Certeau (1994) chama de tática: procedimentos minúsculos e cotidianos que não se conformam e alteram a disciplina dada pelo contexto e são a contrapartida dos praticantes aos processos mudos de ordenação sócio-política.

Por esta situação percebo que um período que poderia ser tomado como apoio ao desenvolvimento profissional docente, ao ser definido como parte da seleção, passa a ter as características de uma avaliação classificatória: 
vigiar, controlar, com relações de poder hierárquicas que geram tensões nesta convivência já que, sendo companheira de trabalho e responsável por orientar, a tutora tem também a função de aprovar ou não o trabalho da professora iniciante.

Uma das tutoras entrevistadas considera que o objetivo da lei que determina o período de práticas é mesmo controlar e avaliar o trabalho e a atuação da profissional novata, porém considera que na prática é também uma oportunidade de aprendizagem e que o tutor deve ser alguém de confiança que a apoie e seja uma referência que pode esclarecer dúvidas e trocar experiências. Reforçando esta última parte da opinião da tutora, as professoras recém-contratadas foram unânimes em dizer que foram tratadas como uma companheira a mais, não como alguém que estaria em uma posição inferior ou dependente.

Porém, por mais que professoras e tutoras (re)inventem no seu cotidiano "mil maneiras de fazer” (Certeau, 1998) as práticas de inserção das primeiras, como o procedimento está vinculado à seleção e não se trata de um programa organizado de apoio aos novos docentes que lhes ofereça desenvolvimento e formação profissional, acaba não sendo suficiente para contribuir com a organização de grupos de reflexão coletiva e para a superação da avaliação como prática fiscalizadora.

Tentando compreender limites e possibilidades do processo de inserção das professoras nas escolas públicas galegas, aprendo com Michel Foucault (1987) sobre como o poder disciplinar é exercido nas pequenas relações obedecendo uma lógica hegemônica na qual fomos formados e à qual estamos acostumados. Porém, o próprio Foucault ensina que esta é uma construção/invenção humana e como tal, o próprio ser humano pode inventar outras formas e fazer diferente. Ao mesmo tempo, aprendo com Morin (1996), a perceber a complexidade da situação, a contradição, a pluralidade e a multidimensionalidade como características da vida. Com este mesmo olhar posso compreender que para além das intenções de que o período de práticas seja de acolhimento e aprendizagem, é explícita a existência nesta proposta de um forte componente de controle das atividades das professoras.

Conforme dito anteriormente, com Certeau (1994) percebo as práticas de usuários, táticas e astúcias, no caso das professoras submetidas à avaliação no seu período inicial da carreira docente, e os efeitos de suas ações que podem inventar maneiras de fazer diferentes das prescritas ou esperadas. Vejo como, na produção de subjetividade controlada, há espaço para produzir também o contrário. Estão presentes nesse cotidiano aspectos disciplinares e hierárquicos na relação entre professoras, tutoras e direção da escola, onde conhecimento e o cargo das segundas pode ser usado para impor às primeiras alguma norma ou procedimento. Simultaneamente, e aí está a complexidade do cotidiano, se rompe com essas práticas, estabelecendo outras em que o diálogo é uma possibilidade de troca entre as educadoras e seus conhecimentos e práticas.

Vejo aí o jogo e o movimento da produção da disciplina e da antidisciplina (SAMPAIO, 2008). Se Foucault ajuda a compreender o funcionamento do poder e o quanto nossas ações carregam mecanismos de controle e disciplinarização (ou seja, como se constrói e se organiza a disciplina em nossa sociedade), Certeau ajuda a mostrar como, apesar desses dispositivos criados socialmente para controlar, os sujeitos vão se mostrando e se recusando a ser meramente dominados e consumidores (ou seja, como se produz a antidisciplina).

Pelo testemunho das entrevistadas, pode-se concluir que prever na lei um período de adaptação, é importante, mas o que conta na prática é a disposição de compartilhar o trabalho e as experiências (das duas partes), de dialogar, de fazer um trabalho coletivo; por parte da escola e das professoras mais experientes, de desejar que a nova professora tenha sucesso, que faça um bom trabalho com o alunado; e, por parte da professora iniciante, de estar aberta a aprender, de perguntar, revelando também o desejo de fazer um bom trabalho com as crianças. Para além das designações legais e das condições objetivas do trabalho e da escola (que comparadas à realidade brasileira podem ser consideradas boas em função da carga horária vinculada exclusivamente a uma escola e à infraestrutura dos centros educativos), o que fez a diferença nesses casos foi o compromisso existente com a aprendizagem e o sucesso dos alunos, por parte da escola e por parte das novas professoras.

\section{Referências}

CERTEAU, Michel de. (1994) A invenção do cotidiano: 1- as artes de fazer. Petrópolis, RJ: Vozes.

EIRÍN NEMIÑA, Raúl; GARCÍA RUSO H.M ${ }^{a}$; MONTERO MESA, Lourdes. (2009) Profesores Principiantes e Iniciación Profesional. Estudio Exploratorio. Revista Profesorado, Granada, v. 13, 1, p. 101-115.

ESPAÑA. Ley Orgánica de Educación 2/2006, del 3 de mayo de 2006. Ministerio de Educación, Cultura y Deporte. Madrid: Boletín Oficial Del Estado 106, del 4-5-2006.

www.boe.es/boe/dias/2006/05/04/pdfs/A17158-17207.p df.

ESPAÑA. Real Decreto 276, de 23 de febrero de 2007. Aprova regulamento de ingresso, acesso e aquisição de novas especialidades e regime de práticas dos corpos docentes. Ministerio de Educación e Ciencia. Boletín Oficial del Estado: Madrid, 2 mar. 2007. n. 53, p. 8915-8938.

www.boe.es/boe/dias/2007/03/02/pdfs/A08915-08938.p df.

FOUCAULT, Michel. (1987) Vigiar e Punir.

Petrópolis: Vozes,.

GALICIA. ORDEN de 23 de marzo de 2013. Oposiciones y Concursos. Consellería de Cultura, Educación y Ordenación Universitaria. Diario Oficial de Galicia: Santiago de Compostela, 4 de abr. 2013 n. 65, p. 9865-9916.

http://www.xunta.es/dog/Publicados/2013/20130404/An uncioG0164-250313-0003_gl.html.

GUARNIERI, Maria Regina. O início da carreira docente: pistas para o estudo do trabalho do professor. (2005). En: (org.) Aprendendo a ensinar: o 
caminho nada suave da docência. p.5-23. Campinas, SP: Autores Associados.

HUBERMAN, Michael. O ciclo de vida profissional dos professores. (2000) En: NÓVOA, António (org.). Vidas de professores. p. 31-61, Porto: Porto Editora.

IMBERNÓN, Francesc. (1994) La formación y el desarrollo profesional del profesorado: hacia una nueva cultura profesional. Barcelona: Graó.

MARCELO GARCIA, Carlos. (1999) Formação de Professores. Para uma mudança educativa. Porto, Portugal: Editora Porto.

MORIN, Edgar. (1996) Ciência com Consciência. Rio de Janeiro: Bertrand Brasil.

NONO, Maévi Anabel; MIZUKAMI, Maria da Graça Nicoletti. (2006) Processos de formação de professoras iniciantes. Revista Brasileira Estudos Pedagógicos. Brasília, v. 87, n. 217, p. 382-400.
NÓVOA, Antonio. (2009) Professores: Imagens do futuro presente. Lisboa, Portugal: Instituto de Educação.

SAMPAIO, Marisa Narcizo. Os caminhos que fazemos ao caminhar: diálogos entre professoras e coordenadoras a partir de registros diários de aula. (2008) Tese (Doutorado em Educação) - Universidade Federal Fluminense, Niterói.

(2015) Inserção de professoras iniciantes em escolas públicas: um olhar sobre as práticas na Espanha. Revista Educação em Questão. Natal, No prelo.

TORRES SANTOMÉ, Jurjo. (2006) Profesoras y profesores en el ojo del huracán. Foro de Educación, Pensamiento, Cultura y Sociedad. Salamanca, $n^{0} .7$ y 8, pp. 81-102. 